NBER WORKING PAPER SERIES

\title{
NEW INNOVATIONS IN PAYMENTS
}

Marc Rysman

Scott Schuh

Working Paper 22358

http://www.nber.org/papers/w22358

\section{NATIONAL BUREAU OF ECONOMIC RESEARCH \\ 1050 Massachusetts Avenue \\ Cambridge, MA 02138 \\ June 2016}

We thank Shane Greenstein, Josh Lerner, Yasin Ozcan and Scott Stern for encouragement and valuable comments. The views expressed herein are those of the authors and do not necessarily reflect the views of the National Bureau of Economic Research.

NBER working papers are circulated for discussion and comment purposes. They have not been peer-reviewed or been subject to the review by the NBER Board of Directors that accompanies official NBER publications.

(C) 2016 by Marc Rysman and Scott Schuh. All rights reserved. Short sections of text, not to exceed two paragraphs, may be quoted without explicit permission provided that full credit, including (C) notice, is given to the source. 
New Innovations in Payments

Marc Rysman and Scott Schuh

NBER Working Paper No. 22358

June 2016

JEL No. L1

\title{
ABSTRACT
}

We discuss prospects for innovation in consumer payment instruments. We discuss recent research into consumer payments and what can be learned about consumer behavior towards new payment options. We consider three new innovations in payments: mobile payments, faster payments and digital currencies. For each, we describe prospects and impediments to adoption.

\author{
Marc Rysman \\ Department of Economics \\ Boston University \\ 270 Bay State Road \\ Boston, MA 02215 \\ mrysman@bu.edu \\ Scott Schuh \\ Federal Reserve Bank of Boston \\ 600 Atlantic Avenue, T-9 \\ Boston, MA 02210 \\ scott.schuh@bos.frb.org
}




\title{
New Innovations in Payments
}

\author{
By Marc Rysman, Boston University \\ and Scott Schuh, Federal Reserve Bank of Boston
}

\begin{abstract}
We discuss prospects for innovation in consumer payment instruments. We discuss recent research into consumer payments and what can be learned about consumer behavior towards new payment options. We consider three new innovations in payments: mobile payments, faster payments and digital currencies. For each, we describe prospects and impediments to adoption.
\end{abstract}

\section{Introduction}

Money and payments have been central to the efficient functioning of markets throughout history, and have been subject to government policy for just as long. Payment may be an afterthought in many transactions, but it is critical nonetheless. Payment instruments, which are methods for transferring money, have also been among the earliest industries to experience digitization, with profound impacts for the payments market and for markets more generally. ${ }^{1}$ The process is ongoing, with numerous new innovations in payments appearing in the near horizon.

This paper briefly discusses this history of digitization in payments, and then turns to evaluate prospects and barriers for several new technological innovations in payments. We focus on retail payments (payments among consumers or payments between consumers and retailers) as opposed to wholesale payments (payments between financial institutions, typically to settle large debts). Understanding prospects for new innovations in payments requires an understanding of how consumers use payments. Recent data collection has enabled new research on consumer usage patterns, and we discuss what can be learned from recent research about adoption prospects. ${ }^{2}$

In particular, research sheds light on important factors for how consumers will evaluate new payment technologies. Some observers might be skeptical that consumers will ever switch away from their current payment options, and indeed, there is no doubt that the current payment system in the United States is fast and efficient in many ways, and serves the needs of consumers as we understand them now. However, we read the research to say that there is

\footnotetext{
${ }^{1}$ In addition, payments innovation can have implications for monetary theory and policy. For example, Hester (1972) discusses how the digitization of payments affects the velocity of money. Townsend (2010) analyzes mobile payments in Kenya and the implications for monetary theory.

${ }^{2}$ Another recent paper that studies innovations in payments is Chakrovorti (2016).
} 
scope for new technologies to make inroads into consumer payment habits, and we believe that small inroads in the near term can lead to transformation in the long term. ${ }^{3}$

We then focus on three important innovations in the payments system that have the potential for widespread adoption, and are the subject of current policy debate. All three make intense use of the Internet and computing power, all three raise important security issues, and all three threaten the traditional business model of banks. The first is mobile payments, the ability to use a mobile telephone to make retail payments. This technology has already achieved popularity in a number of countries, such as Japan, Korea and even Kenya. However, the technology is more recent and less widespread in the United States. Recent new offerings, such as ApplePay, suggest that the market may still move forward. We discuss barriers to innovation in this market, similar to the discussion in Crowe, Rysman and Stavins (2010), and we update that discussion based on recent developments.

The second technology we discuss is the prospects for a real-time payment system in the United States. Even with modern digital payment systems such as the credit card network, the debit card network and the Automatic Clearing House $(\mathrm{ACH}$, used for, among many other things, the direct deposit of paychecks), payments are not settled between banks for at least a day, and often longer, and this has important implications for the use of payments in many contexts. The Board of Governors of the Federal Reserve has issued an initiative for a faster payments system, and various industry respondents, such as the ACH system and The Clearinghouse, are responding. We discuss what the benefits might be of a faster payments system, and the current prospects. Much of our discussion is based on Greene, Rysman, Schuh \& Shy (2014).

The third technology we discuss is digital currencies, such as Bitcoin. Digital currencies are the subject of a great deal of popular coverage, and we focus on what we can add to the discussion. We briefly describe how this type of technology works from the perspective of how it functions for a consumer. We discuss recent trends in the adoption of digital currencies based on data collected by the Consumer Payments Research Center at the Federal Reserve Bank of Boston. Our presentation of consumer trends is a summary of Schuh \& Shy (2016). Another important paper that studies merchant trends in payments is Polasik et al. (2015). ${ }^{4}$

Two broad themes emerge in our paper. First is a tension between the benefits of balkanized proprietary systems and the benefits of market-wide compatibility and standardization. Payments are a network good, and payment systems generally grow more valuable with ubiquitous acceptance and widespread usage. However, the incentive to differentiate is a powerful driver for firms to invest in new products and promote their usage. Can rivalry

\footnotetext{
${ }^{3}$ Several papers we discuss are Koulayev, Rysman, Schuh \& Stavins (2016), Cohen \& Rysman (2013) and Yang \& Ching (2014).

${ }^{4}$ There are certainly more innovations that we could discuss, such as the rise of pre-paid cards, and the spread of on-line banking.
} 
between proprietary systems, such as between Apple and Google in mobile payments (which still rely on the same technology for merchant acceptance), generate a successful market?

Second, new technologies threaten the traditional role of banks in the payments process. Traditional payments, such as credit and debit cards, have been a source of revenue for many banks. These revenue sources appear threatened by the innovations we discuss here. The ability of banks to price or monetize these technologies is unclear, and the innovations are often led by non-bank companies. These developments have implications for bank revenues, prices and also for bank regulation.

\section{The Digitization of Payments}

For most of the twentieth century, payments meant exchanging paper money or checks, which were a paper confirmation of transfers. Even credit card transactions required paper receipts to be shipped among banks. However, digitization came to payments as early as any industry, and indeed, it is difficult to imagine digitization of other industries without prior digitization of the payments industry. We briefly discuss a few important moments in this history.

Credit cards and charge cards originated in the 1950's. However, at that time, using a credit card required a lengthy phone authorization (about four minutes), and then an exchange of paper confirmation among banks. A series of investments brought a fully electronic system to Visa in 1974, which reduced authorization time to 40 seconds and eliminated the exchange of paper entirely. Mastercard made a similar investment shortly after. ${ }^{5}$

At the same time, there was a recognition that the system for personal and business checks, which required the presentation of signed paper checks, was inefficient and difficult to scale up indefinitely. This led to the development of regional Automated Clearing Houses throughout the United States in the early 1970s. ACH systems allowed banks to process payments by exchanging payments in digital form. Today, the ACH system processes common repeated payments such as direct deposit of paychecks and mortgage payments. ${ }^{6}$

Regional ACH systems merged into a national system, coordinated by NACHA, in 1974 . The legislative foundation for NACHA's work towards the digitization of payments came in the Electronic Funds Transfer Act of 1978. Even so, for decades, the ACH system still relied on the exchange of physical digital media, such as diskettes and magnetic tape. It was not until 1994 that the Federal Reserve mandated that all participating banks were required to have an electronic link to the $\mathrm{ACH}$ system and that payment files would be exchanged electronically.

Although the $\mathrm{ACH}$ system could replace checks for many purposes, the checking system still relied on extensive exchange of paper. The next major milestone for checks was the Check 21 Act of 2003, which was meant to move the checking system into the $21^{\text {st }}$ century. The law relaxed the requirement for the presentation of paper checks, and allowed banks to use digital

\footnotetext{
${ }^{5}$ See Evans \& Schmalensee (2005) for a history of payment cards. This discussion draws from page 74.

${ }^{6}$ For a more detailed history, see https://www.newyorkfed.org/aboutthefed/fedpoint/fed31.html.
} 
"substitute checks." This meant that the checking system could be almost entirely digitized. This change is what has enabled modern innovations such as depositing checks through the camera on mobile phone.

We view these developments as the most important ones for modern retail payments, but there are numerous developments that we could discuss, such as the rise of debit cards and the development of entirely electronic exchange systems, such as Paypal.

\section{Academic Research on Consumer Payments}

We begin with a discussion of the academic study of existing payment mechanisms, to see what can be gleaned for new innovations in payments. Fortunately, recent data collection and new academic interest in payments has led to a deeper understanding of how consumers approach payments decisions. This section covers a few recent papers, and discusses their implication for the adoption of new technology. We focus on studies of consumer usage behavior, rather than more general diffusion studies. Research sheds light on two important questions. First, are consumers willing to adopt new technologies? And second, what factors cause consumers to do so? We emphasize two sets of results. The first is that consumers switch among payment types from transaction to transaction, perhaps more than is commonly acknowledged. The second is that consumers use different payment instruments in different contexts, for instance, paying bills with one instrument and paying for retail purchases with another. These results suggest that consumers are willing to adopt new payment innovations even if they are useful in only a limited set of circumstances, but naturally the innovation must provide some use value.

First, are consumers willing to adopt new technologies? Some hold the belief that consumers have set modes of making payments, which do not change in response to circumstance. We argue that the truth is more complex, and there appears to be room for adoption of new technology. Adoption may be limited in the short run, but this can lead to more widespread adoption in the long run.

A problem for new technologies would be if consumers strongly single-home. Single-homing is a concept from the study of platform and two-sided markets that describes when consumers use only one platform (see Rochet \& Tirole, 2006). That is, if consumers prefer to make all payments in the same way, for instance by using a single credit card, then it is difficult for a new technology to displace that credit card, since it must be superior as an overall payment instrument. ${ }^{7}$ If a consumer is willing to multi-home, the consumer might be willing to adopt a new technology even if the consumer uses the new technology in only a few settings.

Do consumers single-home with respect to payment instruments, and in what way? Rysman (2007) considers single-homing with the choice of credit card network. That is, do consumers

\footnotetext{
${ }^{7}$ We can also define single-homing at the level of the type of instrument. For instance, if a consumer always uses credit cards to make payments but holds several credit cards, that is still single-homing of a sort, and it can still limit the ability of a new innovation to be successful.
} 
tend to use only a single payment network, such as Visa, or use multiple networks such as Visa and American Express? Rysman (2007) shows that consumers do tend to single-home. Rysman (2007) uses the Visa Payment Panel Study, in which consumers keep a diary of their payments for a month. For instance, three-quarters of consumers put $97 \%$ or more of their spending in a month on a single network. Further, using data from the Survey and Diary of Consumer Payment Choice, Shy (2013) shows how consumers tend to concentrate most of their card payments on only one type of card (debit, credit, or prepaid) and Briglevics, Schuh, and Zhang (2016) show that consumer homing on single payment instruments occurs when extending the analysis to include cash, checks, and electronic payment methods.

However, the fact that consumers single-home within credit cards is perhaps less important for evaluating new technologies, because credit cards are so similar. A more relevant question for this discussion is whether consumers single-home within payment modes, such as credit versus cash, and cash versus check.

This question is taken up in several papers, such as Klee (2008), Cohen \& Rysman (2013), and Wang \& Wolman (2015). Instead of using diaries of payments, these papers make use of scanner data. This is superior in that it tends to be passive on the part of the consumer, and so is less subject to error and is more complete, although often the scope is more limited than we would find in a consumer survey.

Klee (2008) draws data directly from the register at a retailer. She shows in a regression framework that, on average, consumer payments switch from cash to card as transaction size grows. A drawback of Klee's data set is that it cannot track individuals over time. Thus, retailer scanner data cannot reveal whether there is switching among payment types by individual consumers based on the situations they face, or otherwise address single-homing. As a result, a potential explanation for the pattern in her data is that households never switch between payment instruments, but that some households both use cards and purchase bigger baskets of goods. That would also lead to a correlation between transaction size and card usage.

The extent of within household switching is addressed in Cohen \& Rysman (2013). Cohen \& Rysman draw scanner data from the Nielsen Home-Scan database in which participants scan their grocery purchases with a UPC scanner in their home. Households also submit receipts, which Nielsen uses to identify payment type.

Cohen \& Rysman (2013) present a table showing the extent to which households use cash, card and check. We repeat the table here. For each household, they define the favorite payment instrument based on which instrument is used most often, and then the table shows how much of the population devotes a given share to the favorite. For example, the first column says that only $5 \%$ of the population puts $51 \%$ or less of their transactions on their favorite payment type. In contrast, $75 \%$ of the population puts up to $95 \%$ of their transactions on their favorite payment type. Thus, most households locate the great majority of their payments on their favorite payment type. However, there is still some switching within households, as very few 
households put literally all of their payments on a single instrument. But note that households rarely use three payment types. Half of households do not use a third payment instrument at all, and the next quartile of households use a third favorite payment instrument for less than $1 \%$ of transactions.

Because the data set allows us to track purchases and payment type within a household, we can control for household heterogeneity with a fixed effects approach. A drawback is that we see only grocery purchases, but groceries and supermarkets in particular are important venues for determining household payment choices. Cohen \& Rysman (2013) go on to analyze within household switching using a fixed effects approach, showing the extent that households still switch among payment instruments, and how this relates to transaction size.

It might be a nearly insurmountable barrier for a new payment innovation if it needed to be superior to current payment mechanisms in an overall sense to be successful. However, these papers show that households are sensitive about matching the appropriate payment type to the situation. For instance, many households use cards infrequently, but still use cards for large transactions. We take this to mean that if a new innovation in payments were superior for only a niche of transactions, consumers would still be willing to carry the payment instrument and use it for those transactions. Thus, a new innovation in payments does not need to displace current payment methods entirely to be initially successful.

That is particularly good news, as it appears very difficult to displace a consumer's primary payment instrument. Long panels can be exploited to see how often consumers switch their favorite payment instrument. That is, rather than looking from transaction to transaction to see how often a consumer switches between payment instruments, we can determine a consumer's favorite payment instrument each month or quarter, and see how often the favorite changes. In both Rysman (2007) and Cohen \& Rysman (2013), this appears to be very little, but not zero. For instance, Cohen \& Rysman (2013) determine the favorite payment instrument among cash, check, and card (at grocery stores only) and observe 12 quarters of data. When focusing on favorite payment instruments that get well above $50 \%$ of a households share of payments, Cohen \& Rysman (2013) find that about $85 \%$ of households do not switch their favorite, about $15 \%$ switch once, and less than $1 \%$ switch twice. An implication for innovation is that new innovations will probably achieve relatively low usage for the near term, but this dovetails well with our earlier point that consumers are willing to adopt new instruments for relatively niche uses.

A second point that comes clearly from academic research is the importance of usage in determining which payment mechanisms consumers adopt. Certainly, it is not surprising that consumers are more likely to adopt payment mechanisms that can be used in more environments. However, data analysis reveals the diversity of situations in which consumers find themselves, and their need for multiple payment instruments. 
Koulayev, Rysman, Schuh \& Stavins (2016) (KRSS) analyze these issues in the context of a model that captures both adoption and usage of payment instruments. ${ }^{8}$ They estimate the parameters in their model using the Survey of Consumer Payment Choice, an annual panel study of consumer payment behavior in which consumers report their payments over the previous month. This survey is collected by the Federal Reserve Bank of Boston and the RAND Corporation, and is freely available at the Consumer Payments Research Center at the Federal Reserve Bank of Boston. In the survey, consumers report the number of times they use an instrument in a month, and the number of times in several contexts, such as brick-and-mortar retail, on-line retail, and several bill-pay contexts.

The goal of KRSS is to evaluate substitution patterns among payment instruments, such as debit and credit, particularly motivated by recent regulation of debit card interchange fees by the Board of Governors of the Federal Reserve. Conventional wisdom would suggest that if debit cards became more expensive, most consumers would switch either to cash or credit cards, but KRSS find surprisingly high substitution to checks. It turns out that this is driven by the high use of debit card usage to pay bills. Indeed, the survey data shows that about $20 \%$ of debit card use is in a bill-pay context.

Figure 1 displays an important set of results from KRSS. The figure considers an increase in the cost of a debit card, which leads to a decrease in the use of debit. The table shows how consumers increase their use of other payment instruments. ${ }^{9}$ The figure reports the results separately for retail and bill pay. Summing up over both retail and bill-pay lines for each payment instrument (that is, the solid and dashed lines) leads to $100 \%$, and thus explains the entire decrease in debit card usage. ${ }^{10}$ Note that these results are simulations from an estimated model.

When looking at retail payments, the results have what is perhaps the expected sizes: cash and then credit are the leading alternatives to debit. KRSS show that consumers who do not hold credit cards drive the strong showing of check in retail. However, when we switch to the billpay context, check is the leading alternative to debit cards. Adding up retail and bill-pay lead to the result that check is more popular as a substitute to debit cards than credit cards. Bill-pay also explains the popularity of bank-account deduction as an alternative to debit card usage.

There are several implications for the adoption of new innovations in payments. First, use matters. The paper confirms the basic intuition that a new payment innovation needs to have clear and attractive use applications in order to gain traction. Second, consumers face a wide variety of contexts in which they make payments, and they use quite different instruments in these contexts, varying from on-line bill pay to cards to cash. Third, more specific to the US

\footnotetext{
${ }^{8}$ See also Wakamori and Welte (2012) for a similar model applied to data from a consumer payment diary.

${ }^{9}$ This experiment is motivated by the behavior

${ }^{10}$ In constructing Figure 1, KRSS assume consumers do not cut back on overall payments. Also, Figure 1 reports the $95 \%$ confidence interval for bill-pay. The confidence interval for retail is similar but has been dropped to avoid clutter. See KRSS for more on this.
} 
case, bill-pay matters. Paying bills is an important concern for households, and KRSS shows that bill-pay drives the overall portfolio of payment choices in important ways. Thus, new payment innovations with implications for bill payment may be particularly attractive. We are aware of very few studies that focus on bill-pay, or other data sets that even allow for a detailed study of bill-pay behavior, so this appears to be an important area for future work. Fourth, for the banking industry, technology choice impacts banking revenues. Revenue to banks may differ significantly for debit cards, cash and check, so an intervention that moves consumers from one to the other has important implications for the industry, and ultimately for regulators.

Another interesting question for innovations is whether they can be attractive to older households. There is a sense that older households are "set in their ways," and will not switch to new technologies. However, Yang \& Ching (2014) challenge this conception. They analyze the adoption of ATM cards using panel data from Italy. Indeed, older households are less likely to use ATM cards. However, they argue that this is explained not by high switching costs for older consumers, but by lower expected benefits to be collected over a shorter lifespan. Yang \& Ching use an explicit structural model of dynamic adoption behavior and show that the shorter lifespan over which to realize the benefits of ATM cards explains much of the difference in adoption patterns, leaving relatively little room for higher switching costs as an explanation for the low adoption by holder households. This result changes our view of the barriers to adoption of new technology by older households, and implies that if a new innovation offers large benefits, older households will adopt along with younger ones.

\section{Mobile Payments}

An important and already visible innovation in the payment space is mobile payments. We use the term mobile payments to refer to the use of a mobile telephone as a general-purpose payment device at a retail point-of-sale. ${ }^{11}$ A number of national schemes have been implemented, with varying success and many countries continue to emphasize mobile payments as an important new innovation. In the US, most innovation in this area appears to be led by technology companies rather than by banks, and thus provide a threat to banks both by undercutting their business model and by controlling the customer experience.

First, what are the benefits of mobile payments? Because mobile phones are ever more powerful, and ever more connected, integrating payments into a mobile phone has many potential advantages. Not only could a consumer simply wave a mobile phone in front of a reader and have his bank or payment card account debited automatically, but using the

\footnotetext{
${ }^{11}$ Different definitions might apply. Some refer to any kind of banking via a mobile phone as a form of mobile payment. However, most payments made on a mobile telephone rely on existing payments instruments such as a credit card. Also, mobile telephones can be used to make person-to-person payments (or account-to-account payments) via applications like Paypal and Venmo. In some case, mobile telephones can make payments via text messages, with money drawn either from a bank or the consumer's account with the mobile carrier. Also, there are interesting mobile payment tools that are specific to a seller rather than general purpose. For instance, mobile phones enable payments to Uber from a bank account.
} 
computing and communication power of a mobile phone, the customer could also perform many other activities at the same time. For instance, a consumer could compare prices with prices offered by other local merchants, store the payment record with financial management software, download a warranty or instructional video on how to use a product, and more. Merchants could benefit by having the phones interact with reward or other promotional programs. In addition, this technology could greatly increase the efficiency of the US payment system by offering a payment method that would encourage the transition to electronic payments even for small dollar purchases. Mobile payments are an important step in establishing a digital wallet on a telephone, which contributes to further innovation, such as mobile electronic medical records, which may have further benefits.

Crowe, Rysman \& Stavins (2010) (CRS) evaluate barriers to mobile payments in the US market. Why might mobile payments be slower to take off in the US than Japan? In order to research this topic, CRS conducted interviews with industry participants including executives and trade association representatives from banks and mobile carriers.

CRS finds that standard concerns such as the cost of adoption and network effects play a role. In one popular technological solution, accepting mobile payments requires the merchant to install a reader that can read an NFC (near-field communication) chip on a telephone. Merchants are hesitant to make such an investment without being sure that consumers will actually adopt this product, and naturally consumers do not adopt a product for which there is little use. The cost of installing an NFC chip in a mobile phone is also problematic, although probably now, most current mobile phones come with NFC chips installed.

Implementing a single national mobile payments mechanism most likely will require agreement between mobile carriers and banks that issue cards to consumers. Thus, another important impediment is the unconcentrated nature of the US banking and telecom industries. In Japan, the entire process was driven by NTT, the largest mobile carrier in Japan. In terms of market share, there is no equivalent to NTT in the US. In addition, the US banking industry is drastically less concentrated than in Japan. With so many participants, it is difficult to develop a nationwide open standard.

An alternative would be to implement a proprietary solution, which is how the Japanese market evolved under NTT. However, even if the market were to tend to a proprietary solution (such as Apple Pay) rather than an industry wide agreement, it is difficult to develop valuable partnerships in unconcentrated industries. For instance, suppose that Verizon chooses to work with Bank of America, two of the largest firms in their respective markets. Even so, the combined efforts of these firms could sell only to consumers who hold both products, which might not be large enough. It is difficult to get phone manufacturers to produce telephones for very restricted markets.

Interestingly, there is a standard-setting group working on an open standard for how to implement mobile payments. The Federal Reserve Bank of Boston has played a role in moving 
these discussions forward. ${ }^{12}$ However, CRS finds little general awareness, or even an acknowledgement that an open standard is important for success. Indeed, Japan utilizes a proprietary standard, associated with Sony and NTT.

The explanation that most often came to people's minds in the CRS interviews was the lack of a business plan that determined how banks and carriers would benefit from this technology. Debit and credit cards are a significant source of revenue for a number of banks, and so it was difficult to foresee a plan that was attractive to banks in which that revenue was shared with carriers such as Verizon or producers such as Apple. How such negotiation would play out was a major concern.

However, the CRS interview process led them to conclude that the lack of a business model and the failure of market participants to coordinate is not the source of the problem, but rather the symptom of deeper problems. Ultimately, CRS focus on the widespread use of debit and credit card use in the US, relative to cash-oriented Japan. Mobile payments in Japan largely compete against cash, a much less attractive option than the card systems in place in the US. Thus, in the view of CRS, the widespread use of cards in the US means that US customers are already well served by a payment system that is fast and efficient.

In this view, the lack of a business model that was attractive to various parties is a symptom of the fact that they were bargaining over relatively small surplus that would be created by mobile payments, especially relative to the adoption costs associated with the new technology. In CRS's view, the long-term surplus created by mobile payments is potentially quite large, particularly when one considers the possibility for a fully digital wallet. However, the direction these innovations will take is uncertain. Thus, a better statement than saying that there is little surplus is that there is little certain surplus for the market participants that must invest now. It is unclear whether current firms that must invest in order to make mobile payments a success will be able to profit from the surplus they create.

In such an environment where direct revenue is unclear, one of the main attractions for a firm to invest in mobile payments will be to differentiate its product or service from rivals. That leaves little role for industry-wide agreements, which may not provide sufficient ability for firms to differentiate from each other. ${ }^{13}$ Indeed, visible mobile-payments implementations such as Apple Pay is entirely proprietary. Similar programs are Samsung Pay and Android Pay. Merchants are developing their own program, and mobile carriers have invested in a program called Softpay, but appear to have switched to support Android Pay now. The systems have important differences. For instance, most work with only a subset of banks, and a subset of phones. Samsung Pay has a technology for working with traditional magnetic swipe readers rather than just NFC terminals.

\footnotetext{
${ }^{12}$ For example, see http://www.bostonfed.org/bankinfo/payment-strategies/index.htm.

${ }^{13}$ Augereau, Greenstein \& Rysman (2006) argue that standards that allow firms some scope to differentiate from each other are more likely to succeed.
} 
We wonder how widespread adoption of mobile payments can be if there are many balkanized systems for implementing mobile payments, particularly if that slows merchant adoption of readers. Certainly, it is not impossible to imagine a world of multiple competing propriety mobile payments systems, especially if they do not require separate merchant implementations. But we wonder whether a balkanized system will be as effective in realizing the wider benefits we might associate with mobile payments, such as better communication between merchants and consumers, and the development of digital wallets.

\section{Faster Payments System}

Unlike a number of countries such as the UK and Mexico, the US has no real-time payment system for retail payments, other than cash. By real-time, we mean that the payment is completed almost immediately. That is, at the very least, consumers should be able to authorize a payment and banks should agree that the payment will be made immediately. In addition, the payment should be actually made (called the settlement step for the payment between banks) quickly as well. The only US system that accomplishes this is Fedwire, which is meant for transfers between financial institutions. While consumers perceive debit and credit card payments as immediate, in fact that settlement step often takes several days. Payments through the Automated Clearing House (which is how direct deposit works for salary and mortgage payments, among others) can also take several days to complete.

The implications of this slowness are important. For parties to a one-time transaction who are unlikely to meet again, or for merchants who cannot immediately ship goods and replacement parts until they receive a full payment, the speed of payment may be an important determinant of their business. Even if consumers perceive the payment as immediate, merchants sometimes refuse to ship until banks settle the payment. Further, under a fast payments system, workers can be paid for their most recent work hours. Even for more mundane operations such as paying rent, being able to control the actual day of payment can be important. Indeed, the Board of Governors of the Federal Reserve has pushed forward an agenda of developing a fast payments system for the US. In a consultation paper soliciting public comments, the Federal Reserve, Board of Governors (2013, p.2), sets forth a "vision to improve the speed and efficiency of the U.S. payment system from end to end." 14

An important question is how to go forward with such a proposal. One option is adapting a current system, such as adapting Fedwire to retail payments, or speeding up the ACH system. Another option is investing in an entirely new system. Doing so would require more investment from market participants but the benefits to both consumers and sellers could be large.

Greene, Rysman, Schuh \& Shy (2014) (GRSS) study the implementation of a faster payments system in the United Kingdom, which took place in 2008. An emphasis of GRSS is that the benefits of building a new faster account-to-account payments system may extend well beyond

\footnotetext{
${ }^{14}$ Similar initiatives appear in other countries, such as Australia (Reserve Bank of Australia, 2012).
} 
speed itself. First, current account-to-account systems, such as Paypal and Venmo, have relatively low take-up rates. A new system may be able to overcome the network effects of adoption, and achieve widespread use. A new system could be designed to be more attractive to business-to-business transactions, which appears ripe for digitization, as checks are still a very popular method of business-to-business payments. A new system could be optimized for mobile payments as well. A new system could be designed with modern fraud protection techniques, and would presumably work at all times of the day and year, unlike the $\mathrm{ACH}$ system. A new system could facilitate international transactions by being consistent with international standards, such as ISO 20022, which is currently barely implemented in the US.

Naturally, an important concern with a new system is cost. However, the costs of the UK implementation are surprisingly modest. The UK contracted with a private firm to develop the infrastructure and manage the system for the first several years for a price of about $\$ 65$ million. In an industry in which new systems can easily be measured in billions, this struck us as quite moderate. Additional costs are borne by banks that must connect to the new system. Some banks used this opportunity to overhaul a large set of their accounting system practices, where others did not, so estimating the costs directly associated with this investment is challenging. The system has been successful in achieving a reasonable scale of growth, growing to about a billion transactions in 2013 , representing about $5 \%$ of non-cash payments. The new system has been particularly popular for bill payment and has significantly displaced checks as a method of payment. This point is related to our earlier points about the importance of bill payment, and that consumers are willing to adopt payment innovations with only limited applications. As the system develops more retail applications, such as mobile payments, perhaps it will also threaten card-based systems, but it has not done so yet.

An important part of GRSS is devoted to understanding how these costs would translated to a US setting, with its larger population, larger land area, and much larger number of banks. A challenging question is how such a system should be structured. Similar to the case of mobile payments, developing a workable business model remains an important step. Whether the development of such a system requires government intervention, and whether the system should be owned by banks, or by some third party, or by the government, and what sort of fees should be charged remain important questions. In the UK, under central bank direction, banks fund the system and receive no revenue from it for the start. However, competition concerns recently led the UK Payment System Regulator to direct banks to divest themselves of the firm that manages the Faster Payments System. ${ }^{15}$ The fee structure may evolve as the system ownership changes, and as it grows in popularity.

An important issue is how a new system, whether it is brand-new or whether it is an adaption of an old system, impacts current bank revenue. A system that provides little bank revenue but

\footnotetext{
${ }^{15}$ https://www.psr.org.uk/psr-publications/news-announcements/banks-should-sell-stake-paymentsinfrastructure-help-increase-innovation-competition.
} 
cannibalizes current revenue from cards will meet significant bank resistance. Public statements from representative organizations underscore these points.

GRSS was written in 2014, and this issue continues to evolve. Importantly, the ACH system has implemented plans for a "same-day $\mathrm{ACH}$," which will clear within the day. ${ }^{16}$ While still not a real-time payment system, same-day $\mathrm{ACH}$ certainly enhances the attractiveness of the $\mathrm{ACH}$ system in a number of contexts.

Currently, the plan calls for a 5.3 cent interchange fee. While interchange fees are common for debit and credit cards, there has never been an interchange fee on $\mathrm{ACH}$ or check transactions. The interchange fee is a transaction or value-based fee that goes from the receiving bank to the sending bank. Theoretically, interchange fees can enhance efficiency because they give the payer (who usually decides which payment instrument to use) some of the payee's benefits from a particular choice, which allows the payer to internalize the externality they place on the payee. In practice, interchange fees can also enhance bank revenue under some conditions. ${ }^{17}$

Overall, this is an issue that is very much in flux. The Federal Reserve Bank appears interested in encouraging a faster payments system for the US, and such a system exists in a number of other countries. GRSS suggest the potential benefits can be large, and perhaps extend well beyond speed itself. Important questions remain, such as whether to build a new system or adapt an old system, how such a system will be managed and funded, and what fee structure such a system may use. Another important question is how much government intervention is necessary and desirable to move this market forward.

\section{Virtual Currencies}

A striking new phenomenon is what is known as virtual currencies, digital currencies, or cryptocurrencies, highlighting different features. ${ }^{18}$ National currencies have many of these features, so it is difficult to come up with an appropriate name. Bitcoin is the most well known, but there are many others; Schuh and Shy (2016) report about 700, and entry of new ones is not difficult.

Bitcoin can be thought of as consisting of two main innovations. The first is a method for assigning ownership over an asset. Assets are governed by a "block chain" of information describing the account that the asset is held by, and the history of transactions of that asset. Only the account holder can move the asset to another account. This is done by sending a message to servers that process Bitcoin transactions. This process is decentralized. It is somewhat analogous to sending an e-mail. The transfer message involves intense

\footnotetext{
${ }^{16}$ The ACH system is really two systems. The first is run by the Federal Reserve (FED ACH), and processes about $70 \%$ of the transactions. The second is the Electronic Payments Network (EPN), and it primarily serves large banks. FED-ACH has adopted plans for a same-day ACH option, and EPN plans to take up this issue shortly.

${ }^{17}$ See Rysman \& Wright (2014) for a full discussion of the economics of two-sided markets and interchange fees in the context of payments.

${ }^{18}$ For reviews, see Bohme, Christin, Edelman and Moore (2015) and Halaburda \& Sarvary (2015).
} 
cryptography, and so requires substantial computational power to process, and thus takes nontrivial time to process. Ten minutes would not be unusual.

This approach to registering ownership could be applied to any sort of asset, such as real estate, automobiles, art or US dollars. The second innovation is inventing a currency to be traded under this system, such as Bitcoin. Under Bitcoin, computers that solve cryptographic problems that transfer assets lead to the generation of new Bitcoins, which are assigned to the owners of the computers. Thus, computer owners are paid in Bitcoins for providing processing power. This process is referred to as mining.

Virtual currencies have attracted a great deal of attention in the press, and policy makers such as central banks watch this closely as well (see Badev \& Chen 2014). Prospects for virtual currencies for retail payments are unclear. The transfer of Bitcoins perhaps takes too long to be useful at the point-of-sale, and the value it offers over current card systems is unclear. Even merchants that accept Bitcoins as payment tend to employ a payment processor that immediately converts Bitcoins to dollars. Thus, while the consumer pays in Bitcoin, it is unclear that the merchant can be said to accept Bitcoins. Some believe that the leading edge for virtual currencies will be international transfers, which are priced fairly high by banks. But prices can change in the face of competition, and it is unclear whether the system for the international transfer of national currencies is more expensive than that of Bitcoins at a technical level.

On the other hand, virtual currencies have attracted serious investment from people who believe that virtual currencies have an important future. Rather than go further into the debates about the prospects for virtual currencies (and associated issues of security, crime and monetary policy), we focus on the use of virtual currencies now. The SCPC (used by KRSS) currently includes questions about virtual currencies, and Schuh and Shy (2015) present tables based on these answers. Here, we briefly summarize their findings.

Schuh \& Shy (2016) find that $43 \%$ of 2015 households report being aware of virtual currencies, up from about $40 \%$ in 2014 . But even among those who are aware, the vast majority report being only "slightly familiar" or "not at all familiar" with virtual currency. Only about $1 \%$ of consumers report owning a virtual currency, the majority of them being Bitcoin owners, and at least $0.34 \%$ of consumers (one in three owners) discard virtual currency each year. At this time these estimates were obtained, the value of a Bitcoin was about $\$ 300$. However, estimates of Bitcoin holdings (in coins or dollars) are not particularly reliable, perhaps because of the unfamiliarity of consumers with virtual currencies. Table 2 shows the incidence of use, and the context. According to the estimates, about half to three-quarters of holders of virtual currency report having actually used a virtual currency in the previous year. Of those, about half report having used virtual currency to pay a merchant, about half report having used virtual currency to pay a person (not a business), and about one third do both. Obviously, it is difficult to infer too much from the answer of half of a percent of survey respondents. But in 2014 , only $46 \%$ of virtual currency holders reported having used a virtual currency in the previous year, relative to $75 \%$ in 2015 . Thus, it does appear that the use of virtual currency may be increasing over time. 


\section{Conclusion}

Payments systems have undergone continuous digitization and innovation for the last 40 years. In this paper, we discuss the prospects for several new innovations in payments. Academic research on consumer behavior with regard to payments suggests a willingness to experiment with new innovations, at least to a limited extent, when a clear use case is present.

We discuss three innovations: mobile payments, faster payments, and virtual currencies. Each has the prospect for widespread adoption, and for each, the most important implications perhaps fall outside of their direct application. For instance, paying with a mobile telephone may have special convenience, but some of the most important implications are probably based around increased and long-lasting buyer-seller communication, and the development of digital wallets. A new faster payments system is likely to be not only faster, but also more convenient for modern applications, and would be well adapted for B2B payments and international transfers. Virtual currencies are associated with enormous speculation about how they might transform the political landscape with respect to payments and monetary policy.

All three technologies affect banks in complex ways. Banks derive revenue from their role in the payments process, particularly on credit and debit cards. In contrast, banks have not been able to generate comparable revenue from new developments such as mobile and faster payments, or digital currencies. Indeed, technology companies appear to be leading the way in these areas. To the extent that card revenues are threatened by these developments, banks may be put in a difficult situation.

Furthermore, bank operations as a payment provider tend to be more heavily regulated than those of technology companies, which makes it difficult for banks to respond to innovation. Banks do not appear able to block the development of these technologies, and indeed, there are many instances of banks investing to be part of the development of these technologies. Regardless of any bank investment though, the centrality of banks in the payments process may be in question, which has implications for wider bank business strategy, as well as payments regulation.

The current milieu for payments has many players, from both within and outside of the traditional financial services industries, and these many players bring many potential innovations, some that directly compete with each other. In this state of competition between balkanized networks, it may be difficult for a new technology to emerge as dominant, even if the technology is somehow superior. However, at the same time, it does not appear that any firm has the ability to block a new efficient technology. In fact, we might characterize the current setting as very creative, where a transformative technological innovation would have at least an opportunity to succeed. However, it is unclear that competition between balkanized systems can deliver the widespread benefits (such as the transition to a digital wallet) that we might associate with a standardized system, or set of compatible systems. 
The payments system is transformed from what it was 50 years ago, and it seems clear that the transformation will continue into the future. The digitization of other parts of the economy interacts with the digitization of payments, with each supporting innovation in the other. "Digital convergence" of all types of media into a single digital stream of information has been widely recognized. Perhaps we should recognize that convergence includes payments as well, in which account holdings and transfers are another type of information to be digitized and communicated over modern computer systems.

Table 1: Concentration of Payments on a Favorite Pay Types

\begin{tabular}{|l|l|l|l|l|l|l|}
\hline Percent of Population & 5 & 10 & 25 & 50 & 75 & 90 \\
\hline Percent on Favorite Pay Type & 51 & 56 & 68 & 85 & 95 & 100 \\
\hline Percent on Favorite Two Pay Types & 88 & 94 & 99 & 100 & 100 & 100 \\
\hline
\end{tabular}

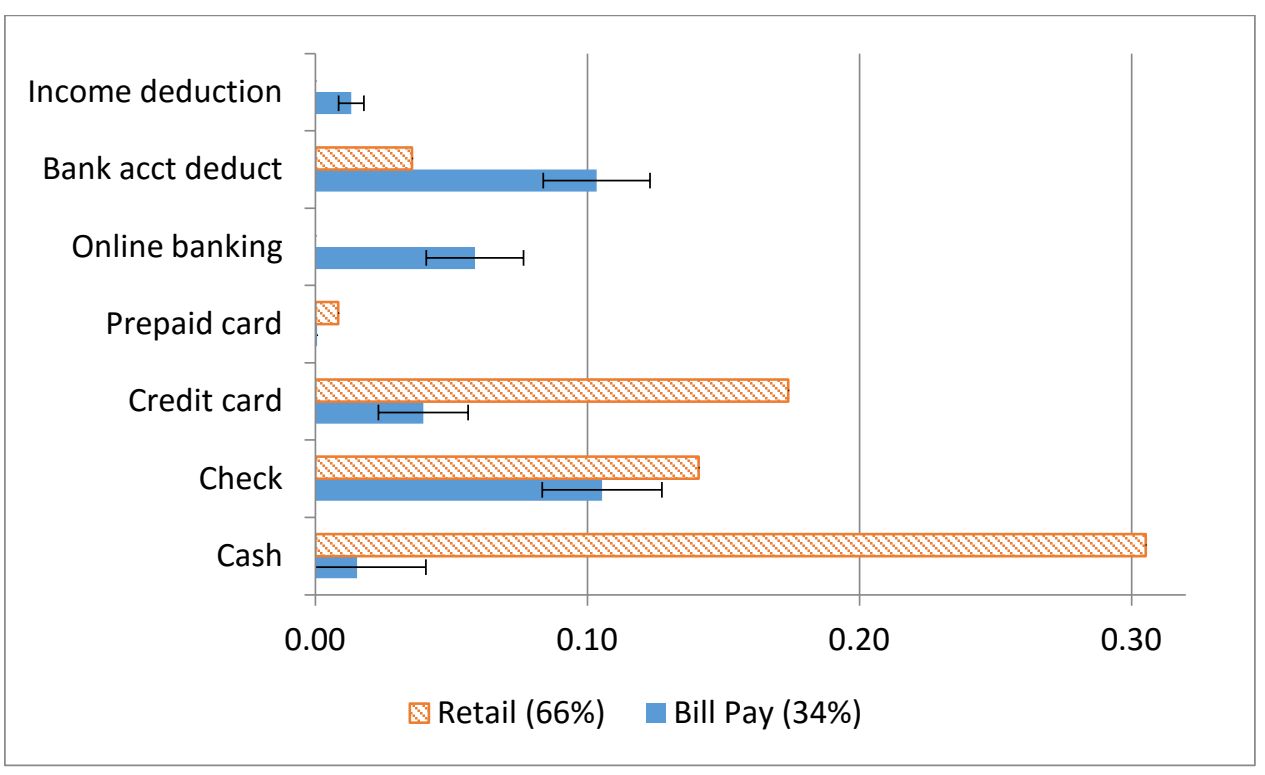

Figure 1: Substitution Patterns in Response to an Increase in the Cost of Debit Card Usage 
Table 2: Incidence of use and payee for virtual currency

Incidence of use and payee for virtual currency

Percentage of adopters. SCPC Tables 19-27.

\begin{tabular}{|c|c|c|c|}
\hline \multirow[t]{2}{*}{ Incidence of use and payee } & \multicolumn{2}{|c|}{2014 SCPC } & \multirow{2}{*}{\begin{tabular}{|c|}
2015 SCPC \\
Oct
\end{tabular}} \\
\hline & Oct & Jul 2015 & \\
\hline 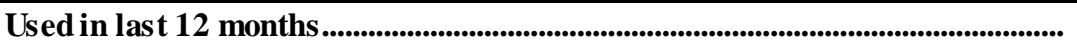 & 45.7 & 75.1 & 42.6 \\
\hline Bitcoin.................................... & 39.8 & 79.9 & 46.1 \\
\hline Other virtual currency ${ }^{*}$ & 31.6 & 64.4 & 49.6 \\
\hline 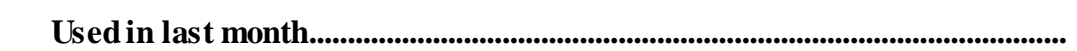 & & 72.5 & 38.0 \\
\hline Bitcoin & & 74.5 & 40.4 \\
\hline Other virtual currency & & 55.7 & 49.6 \\
\hline \multicolumn{4}{|l|}{ Payee } \\
\hline Merchant & & 40.0 & 52.0 \\
\hline Person............................ & & 58.2 & 42.7 \\
\hline Both & & 24.7 & 39.4 \\
\hline
\end{tabular}

* Excluding incorrectly identified 


\section{Bibliography}

Augereau, A., Greenstein, S., \& Rysman, M. (2006). Coordination versus differentiation in a standards war: 56K modems. The RAND Journal of Economics, 37(4), 887-909.

BOG. (2013). Strategies for Improving the U.S. Payment System.

Badev, A., \& Chen, M. (2014). Bitcoin: Technical Background and Data Analysis. FEDS Working Paper No. 2014-104.

Bohme, R., Christin, N., Edelman, B. \& Moore, T. (2015). Bitcoin: Economics, Technology and Governance, Journal of Economic Perspectives, 29(2), 213-238.

Briglevics, T., Schuh, S., \& Zhang, D. H. (2016). Consumer Homing and Payment Instrument Choice. Working Paper.

Chakrovorti, S. (2016). New Payment Technologies: Back to Basics. Working Paper.

Cohen, M. A., \& Rysman, M. (2013). Payment Choice with Consumer Panel Data. Working

Paper.

Crowe, M. D., Rysman, M., \& Stavins, J. (2010). Mobile Payments in the United States at Retail

Point of Sale: Current Market and Future Prospects. FRB of Boston Public Policy Discussion

Paper No. 10-2.

Evans, D. S., \& Schmalensee, R. (2005). Paying with Plastic: The Digital Revolution in Buying and Borrowing (2nd Edition). MIT Press.

Greene, C., Rysman, M., Schuh, S. D., \& Shy, O. (2014). Costs and Benefits of Building Faster Payment Systems: The U.K. Experience and Implications for the United States. FRB of Boston Research Paper Series Current Policy Perspectives No. 14-5.

Halaburda, H. \& Sarvary, M (2015). Beyond Bitcoin: The Economics of Digital Currencies. Palgrave.

Hester, D. (1972). Monetary Policy in the "Checkless" Economy. Journal of Finance, 27, 279-293. Jack. W., Suri, T. and Townsend R.M. (2010). Monetary Theory and Electronic Money:

Reflections on the Kenyan Experience. Economic Quarterly. 96, 83-122.

Klee, E. (2008). How people pay: Evidence from grocery store data. Journal of Monetary Economics, 55(3), 526-541.

Koulayev, S., Rysman, M., Schuh, S., \& Stavins, J. (2016). Explaining Adoption and Use of Payment Instruments by U.S. Consumers. RAND Journal of Economics. 47, 293-325.

Polasik, M., Piotrowska, A. I., Wisniewski, T. P., Kotkowski, R., \& Lightfoot, G. (2015). Price Fluctuations and the Use of Bitcoin: An Empirical Inquiry. International Journal of Electronic Commerce, 20(1), 9-49.

RBA. (2012). Strategic Review of Innovation in the Payments System: Conclusions.

Rochet, J., \& Tirole, J. (2006). Two-sided markets: A progress report. The RAND Journal of Economics, 37(3), 645-667.

Rysman, M. (2007). An Empirical Analysis Of Payment Card Usage. Journal of Industrial Economics, 55(1), 1-36.

Rysman, M., \& Wright, J. (2014). The Economics of Payment Cards. Review of Network Economics, 13(3).

Schuh, S., \& Shy, O. (2016). U.S. Consumers' Adoption and Use of Bitcoin and other Virtual Currencies. Working Paper. 
Shy, O. (2013). How Many Cards Do You Use? FRB of Boston Working Paper No. 13-13.

Wakamori, N., \& Welte, A. (2012). Why Do Shoppers Use Cash? Evidence from Shopping Diary Data. Working Paper.

Wang, Z., \& Wolman, A. L. (2015). Payment Choice and Currency Use: Insights from Two Billion Retail Transactions. Working Paper.

Yang, B., \& Ching, A. T. (2014). Dynamics of Consumer Adoption of Financial Innovation: The Case of ATM Cards. Management Science, 60(4), 903-922. 